\title{
Impact of Stress on Immune Response of Breast Cancer Women After Mastectomy
}

\author{
Amal Mohamed Gamal ${ }^{1}$, Sanaa Ibrahim Abd El-Gaffar ${ }^{2}$ \\ ${ }^{1}$ Maternity \&Newborn Health Nursing Department, Faculty of Nursing, Menoufia University, Menoufia, Egypt \\ ${ }^{2}$ Medical Surgical Nursing Departmen, Faculty of Nursing, Menoufia University, Menoufia, Egypt \\ Email address: \\ dr.amal_gamal@yahoo.com (A. M. Gamal), sanaaibrahim64@ymail.com (S. I. A. El-Gaffar) \\ To cite this article: \\ Amal Mohamed Gamal, Sanaa Ibrahim Abd El-Gaffar. Impact of Stress on Immune Response of Breast Cancer Women After Mastectomy. \\ American Journal of Nursing Science. Vol. 4, No. 4, 2015, pp. 182-189. doi: 10.11648/j.ajns.20150404.16
}

\begin{abstract}
Aim of the study was to determine the impact of stress on immune responses of breast cancer women after Mastectomy Materials and method: study was carried out on a convenient sample of 60 adult women diagnosed as breast cancer for stage II or III and scheduled for mastectomy at Oncology University Hospital of Menoufia A descriptive design was used. Two tools; were utilized to collect data related to this study were (1) Stress Assessment Scale, and (2) Immune Response Assessment Questionnaire. Results: revealed that $46.7 \%$ of breast cancer women in the study aged between (45 - to less than 55) years, $80.0 \%$ were married, $63.3 \%$ lived in rural areas, $50.0 \%$ monthly income between (150 - less than 300) Egyptian pounds, $40.0 \%$ were illiterate, $36.7 \%$ of the sample had sever degree of stress at preoperative assessment while $56.7 \%$ had sever degree of stress at post operative assessment, there was negative statistically significant correlations between total stress and immune responses were T lymphocytes, CD4 helper, CD56 NK cell, and CD14 Monocytes in pre operative assessment. And T lymphocytes, CD4 helper, CD8 Cytotoxic, CD56 NK cell, and CD14 Monocytes in post operative assessment. Conclusions: the higher the degree of stress, the lower the values of T Lymphocytes, CD4 helper, CD8 Cytotoxic, CD56 NK cells, and CD14 Monocytes. Supporting cancer women during treatments through instructing their psychological and physical well-being. Recommendation: Further researches are needed with large sample size and control group.
\end{abstract}

Keywords: Breast Cancer. Women, Immune Response, Mastectomy, Stress

\section{Introduction}

Breast cancer is an unregulated growth of abnormal cells in breast tissue. It happens when cells in the breast begin to grow out of control and can then invade nearby tissues or spread throughout the body ${ }^{(l)}$. The diagnosis of breast cancer may affect on women from many aspects of their lives. There are primary issues about self image, fear of recurrence, and the need for continued treatment, as well as issues related to daily activities, career, and relationships. Yet after the immediate crisis of the diagnosis most women faces long-term psychological or sexual problems. The breasts are a profound source of female self-image. Cancer of the breast may seriously affect a women's perception of her identity, and breast loss can be very psychologically damaging ${ }^{(2)}$ In the United States, breast cancer is the third most common cause of cancer death (after lung cancer and colon cancer). In 2007, breast cancer is expected to cause 40,910 deaths ( $7 \%$ of cancer deaths; almost $2 \%$ of all deaths)
(3). In Egypt, breast cancer is the most common cancer among women, representing $18.9 \%$ of total cancer cases $35.1 \%$ in women and $2.2 \%$ in men. Statistical records of the Egyptian National Cancer Institute illustrates 180.000 annual cases of breast cancer occurs during the year 2001 ${ }^{(4)}$. Breast cancer is the most prevalent cancer among Egyptian women and constitutes $29 \%$ of National Cancer Institute cases ${ }^{(5)}$. According to the statistical record of Menoufia University Hospital of women were admitted for the last 6 months of the year $2004^{(6)}$

Surgical treatment of breast cancer is the most frequently used treatment for cancer and has changed significantly in recent years. The preferred method of treatment for many women with early breast cancer is conservative surgical therapy principally lumpectomy and axillary dissection followed by breast irradiation. This technique allows women with different forms of breast cancer to conserve 
their breasts. For women who scheduled for mastectomy surgery, immediate reconstruction of the breast is now routinely performed with a prosthetic implant or autologous tissue ${ }^{(7)}$.

The extent of the surgical intervention is determined by the clinical presentation and by the possibility of resecting the tumor with clean margins. The goal is to preserve the breast, because there is no evidence that a mastectomy is more beneficial than lumpectomy plus radiation therapy. However, because of size or the multifocal or metacentric extent of disease, mastectomy may be necessary to provide adequate tumor removal ${ }^{(8)}$.

The loss of body parts can give rise to grief for loss of body image or function, or both. Stress, depression, and sexual problems are related to the magnitude and type of loss as well as the personal vulnerability of the women. Many women are not satdisfied with any prosthesis that they are offered, and they may attempt to avoid facing the painful reality of their loss by refusing to look at their chest wall, dressing and undressing in the dark, and minimizing the time that they can spend in bathing. These activities reflect an avoidance style of coping ${ }^{(9)}$.

Women with cancer can have significant lifestyle changes as a result of their condition. They will have poor eating habits because of nauseating feelings which were not directly related to their treatments or conditions. They have disturbed sleep patterns, such as insomnia or waking up early. They also frequently develop drug problems. All of these factors seem to add additional stresses which impact the physiological effects. Targeting these stresses has had positive results on the health of individuals ${ }^{(10)}$.

Stress is a state produced by a change in the environment that is perceived as challenging, threatening, or damaging to the person's dynamic balance or equilibrium. So there is an actual or perceived imbalance in the person's ability to meet the demands of the new situation. The change or stimulus that evokes this state is the stressor ${ }^{(11)}$. The immune system is connected to the neuroendocrine and autonomic systems. Lymphoid tissue is richly supplied by autonomic nerves capable of releasing a number of Different neuropeptides that can have a direct effect on leukocyte regulation and the inflammatory response. Neuroendocrine hormones released by the central nervous system and endocrine tissues can inhibit or stimulate leukocyte function. The wide variety of stressors people experience may result in different alterations in autonomic activity and subtle variations in neurohormone and neuropeptide synthesis. All of these possible autonomic and neuroendocrine responses can interact to initiate, weaken, enhance, or terminate an immune response ${ }^{(12) \text {. }}$

The study of the relationships among the neuroendocrine system, the central and autonomic nervous systems, and the immune system and the effects of these relationships on overall health outcomes are called psychoneuroimmunology. Because one's perception of events and coping styles determine whether and to what extent, an event activates the stress response system, and because the stress response affects immune activity. So one's perceptions, ideas, and thoughts can have profound neurochemical and immunologic consequences ${ }^{(13)}$.

The immune system is important to cancer women in many ways. The cancer can weaken the immune system by invading the bone marrow where the cells that help fight infection are made. This happens most often in leukemia or lymphoma. But it can happen with other cancers too. Chemotherapy and radiotherapy can weaken immunity by causing a drop in the number of white blood cells made in the bone marrow; this effect on the bone marrow is temporary. Some cells of the immune system can recognize cancer cells as abnormal and kill them, as well as prevent cancer recurrence ${ }^{(14) \text {. }}$

Nurses play an important role in improving body image and psychological state to help the women retain control by encouraging independence, participation in self care, and decision making. Psychological support of the patient is an important aspect of cancer care, many women with cancer are cured or their diseases are controlled for long period of time. In light of this trend in cancer treatment, emphasis must be placed on maintaining psychological well-being and optimal quality of life ${ }^{(15)}$. Significance of the study :-it has been observed over a period of four years working in surgical departments that there are many women admitted to oncology surgical department with the diagnosis of breast lump and scheduled for surgical treatment .In addition there was a fear of adjacent treatment that follow the operation such as chemotherapy or radiotherapy and fear of recurrence and death, all of these lead to stress and anxiety for women .Psychological state can have effect on health in addition to immune system which lead to the progression of disease and metastasis .

\section{Aim of the Study}

The aim of the present study (was) to determine the effect of stress on immune responses of breast cancer women after mastectomy

\section{Research Questions}

1. What are the effects of stress on the immune responses after surgical treatment of breast cancer women?

2. Is there relationship between stress and immune responses for women undergoing surgical removal of the breast?

\section{Material}

\subsection{Research Design}

A descriptive correlational research design was utilized.

\subsection{Setting}

This study was conducted at the Oncology Hospitals and the surgical department of Menoufia University Hospitals,. 
Menofia Governorate, Egypt. Both of These places are considered main resources for women with breast cancer.

\subsection{Subject}

A convenient sample of 60 adult female women diagnosed as breast cancer for stage II or III and before scheduling for mastectomy. They were selected according to the following criteria:

1. Age from 35-65, as breast cancer is more common in this age group.

2. There was no metastasis and the women didn't start any adjuvant treatment as they may have an effect on the immune system.

3. The patients with immunosuppressant drugs or diseases and malnutrition were excluded from the study as it may have an impact on the immune response.

4. Free from any other associated diseases as diabetes.

\subsection{Tools}

For the purposes of the study and to collect the necessary data, two tools were developed and utilized by the researchers based on review of literature.

Tool I: Stress Assessment Scale: the impact of event scale - Revised

This tool was developed by Weiss \& Marmar, (1997) ${ }^{16}$ and was modified and translated into Arabic by the researchers to assess current subjective data related to stress for any specific life event. The scale consists of 22 items which was rated on 5 point, where: 0 illustrate (not at all), 1 (a little bit), 2 (moderately), 3 (quite a bit), and 4 (extremely). A score of stress: (0-11) referred to sub Clinical range of stress, (12-33) referred to mild range, while (34-55) referred to moderate range of stress, and (56-77) referred to severe range of stress.

Tool II: Immune Response Assessment Sheet:-

Interviewing questionnaire was constructed and developed by the researcher after reviewing of related literature to assess the immune response for women undergoing mastectomy. It consists of three parts.

Part One: Biosociodemographic characteristics:

It recorded data about the following items: personal data as age, sex, level of education, occupation, marital status, monthly income, family member. Items about clinical data such as woman history of chronic diseases, family history of breast cancer, and family history of cancer at any part of the body, tumor stage at diagnosis, site of breast cancer, affected quadrant, and type of mastectomy.

Part Two: laboratory evaluation of the immune system:-

This part was developed by the researcher and includes the quantitative measurements to evaluate the immune system O'Leary ${ }^{17}$ (1990). It includes the following:-

a) Total leukocyte counts

b) Percentage of T Lymphocytes

c) Cellular immunity:

- CD4 Helper

- CD8 Cytotoxic

- CD56 NK T cells
- CD 14 Monocytes

- B Lymphocytes (CD 19 and CD 20)

d) Immunoglobulins and immune proteins:

- Serum level of IgM and IgG

- Serum level of complement $(\mathrm{C} 3, \mathrm{C} 4)$

* Evaluation of peripheral blood leucocytes Markers expression by flow cytometery:

Single color analysis was performed using flow cytometery (Becton Dickinson FACS Calibur) with FITC and PE conjugated monoclonal antibodies of CD4, CD8, CD56, CD 14, CD 19 and CD 20 respectively.

Part Three: wound assessment:

The wound assessment Scale it was developed by Gaber, (1986)18 and used by the researcher to assess wound inflammation, extent of inflammation, pain in the wound, wound discharge, type of discharge, and redness \& hotness, the extent of inflammation was measured with ruler. As wound assessment is a good indicator for immunocompromised.

\section{Methods}

1. Each women who agreed to participate in the study and fulfilled the inclusion criteria was interviewed individually twice by the researcher after attending surgical department of Menofia University Hospitals; the necessary data was collected. The first interview was done at pre-operative period after diagnosing breast cancer and the day before scheduling for mastectomy to collect baseline data on biosociodemographic data, stress assessment, nutritional assessment scale, and blood sample was withdrawn for assessment of the immune system. The interview took about 30 minutes using tool I, tool II part 1, part 2 and tool III. The researcher emphasized to them that the participation in the study is entirely voluntary and confidentiality will be maintained.

2. The second interview was done in the post-operative period after 2 weeks at oncology hospital and before starting any adjuvant treatment, the women with mastectomy were interviewed by the researcher to collect data about stress, nutrition, and sample of blood was withdrawn again for assessment of the immune system using tool I, and tool II part 2,

The surgical wound was assessed at 5th post-operative day as the immediate post operative inflammatory phase of healing occurring around days 1-3 following surgery using tool II part 3.

3. Comparison was done between stress and immune assessment at pre and post operative period to determine the effect of stress on immune response after surgical treatment of breast cancer women

4. All tools except wound assessment were tested by eleven experts in the field included nurse educator and surgical specialist, modifications were done accordingly. 


\section{Statistical Analysis}

Results were collected, and tabulated, statistically analyzed by IBM personal computer and statistical package SPSS version 11. Using percentage (\%), mean ( $\mathrm{x}$ ) and standard deviation (SD). Chi-square test $(\chi 2)$ : was used to study association between two qualitative variables.

- Paired t-test: is a test of significance used for comparison between two related groups having quantitative variables. ANOVA test: is a test of significance used for comparison between means. Pearson correlation (r): is a test used to measure the association between two quantitative variables.

\section{Results}

Regarding Sociodemographic characteristics of breast cancer women undergoing surgical treatment. In relation to age most of studied sample $(46.7 \%)$ ranged between the age group of 45 to less than 55 years. As regards marital status, $80.0 \%$ were married, $13.3 \%$ were widow, and only $6.7 \%$ were single. Regarding to number of children $40 \%$ had $4+$, while $30 \%$ had 3 children, $13.3 \%$ had 2 children, $6.7 \%$ had one child, and $10 \%$ had no children. Regarding to educational level $40.0 \%$ was illiterate while $23.3 \%$ were secondary and university graduates. In relation to employment status $70.0 \%$ were house wives,

Thirty percent $(30.0 \%)$ were employed. Regarding place of residence $63.3 \%$ lived in rural areas, while $36.7 \%$ lived in urban areas. Referring to monthly income of subjects $50.0 \%$ a monthly income between (150 - less than 300) Egyptian pounds, $36.7 \%$ had a monthly income between (300 - less than 500) Egyptian pounds, where 13.3\% had an income $500+$ Egyptian pounds. As regards family member

Graph one: Shows (not in the past) distribution of women according to stress assessment of the sample at pre and postoperative period. In the pre-operative assessment $26.6 \%$ of the sample had mild stress, while $36.7 \%$ had moderate stress, more over $36.7 \%$ had severe stress. In the post-operative assessment the majority of the sample $56.7 \%$ had severe level of stress while $26.6 \%$ had moderate stress and $16.7 \%$ had mild stress.

Table one: shows (not in the past) the relation between stress and immune response among breast cancer women in the pre-operative period. There was statistical significant difference between stress and immune response in the preoperative period. The higher the degree of stress the lower the mean values of $\mathrm{T}$ lymphocytes \%, (write it) $\mathrm{T}$ lymphocytes absolute, CD4 helper \%, CD4 helper absolute, CD56 NK \%, CD56 NK absolute, CD14 monocytes \%, and CD14 monocytes absolute as $\mathrm{P}=0.003,0.009,0.033,0.010$, $0.003,0.004,0.015$, and 0.037 respectively. While There was no statistical significant difference between stress and immune response in the preoperative period for Total
Leukocyte Counts, CD8 cytotoxic \%, CD8 cytotoxic absolute, B lymphocytes (CD19\&CD20) \%, and B lymphocytes (CD19\&CD20) absolute, IgM, IgG, C3 and $\mathrm{C} 4$ as $\mathrm{P}=0.32,0.78,0.073,0.50,0.98,0.75,0.10,0.18$, and 0.38 respectively.

Table one: shows the relation between stress and immune response among breast cancer patients in the post-operative period. There was statistical significant difference between stress and immune response in the post-operative period. The higher the degree of stress the lower the mean values of $\mathrm{T}$ lymphocytes \%, T lymphelper \%, CD4 helper absolute, CD8 cytotoxic \%, CD8 cytotoxic absolute, CD56 NK \%, CD56 NK absolute, CD14 monocytes \%, and CD14 monocytes absolute as $\mathrm{P}=0.007,0.025,0.001,0.002,0.040$, $0.009,0.001,0.001,0.007$, and 0.016 respectively

While There was no statistical significant difference between stress and immune response in the post-operative period for Total Leukocyte Counts, B lymphocytes (CD19\&CD20) \%, and B lymphocytes (CD19\&CD20) absolute, $\operatorname{IgM}, \operatorname{IgG}, \mathrm{C} 3$ and $\mathrm{C} 4$ as $\mathrm{P}=0.091,0.65,0.27,0.63$, $0.52,0.052$, and 0.45 respectively

Table two: shows the relation between stress and wound assessment among breast cancer women in the postoperative period. Regarding pain in the wound more than half of the sample $82.4 \%$ presented with pain in the wound had severe level of stress with statistical significant difference as $\mathrm{P}=0.020$. While there was no statistical significant difference between stress and wound inflammation, extent of inflammation, wound discharge, type of discharge, and redness $\&$ hotness as $\mathrm{P}=0.70,0.62$, $0.063,0.12$, and 0.050 respectively.

Table three showed Correlation between stress and laboratory investigations among breast cancer women in the post-operative period. There was statistical significant negative correlation between stress and post-operative laboratory investigations of the studied sample for hemoglobin, hematocrit, blood urea and serum albumin as $\mathrm{P}=0.014,0.002,0.042$ and 0.013 respectively. While there was no statistical significant correlation between stress and post-operative laboratory investigations for serum creatinine, and albumin/globulin ratio as $\mathrm{P}=0.589$, and 0.076 respectively.

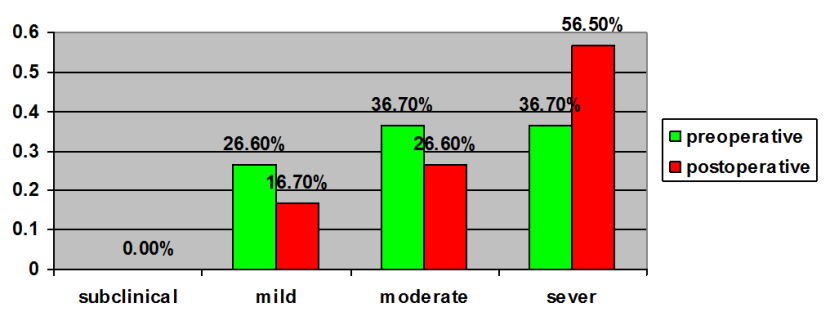

Graph (1). Distribution of Study Women According to Stress Assessment Level at Pre and Post-operative Phases. 
Table (1). Relation between Stress and Immune Response among Breast Cancer Women in the Pre-operative Phase.

\begin{tabular}{|c|c|c|c|c|}
\hline \multirow{4}{*}{ Pre-operative assessment of immune response } & \multicolumn{3}{|c|}{ Degree of Pre-operative stress assessment } & \multirow{4}{*}{ F test/ P Value } \\
\hline & \multirow{3}{*}{$\begin{array}{l}\text { Mild } \\
(n=16) \\
X \pm S D\end{array}$} & \multirow{2}{*}{$\begin{array}{l}\text { Moderate } \\
(\mathrm{n}=\mathbf{2 2})\end{array}$} & \multirow{2}{*}{$\begin{array}{l}\text { Severe } \\
(n=22) \\
\end{array}$} & \\
\hline & & & & \\
\hline & & $\mathrm{X} \pm \mathrm{SD}$ & $\mathbf{X} \pm$ SD & \\
\hline - Total leukocyte counts $(\mathrm{KP} / \mathrm{L})$. & $6.28 \pm 0.90$ & $6.25 \pm 0.95$ & $5.71 \pm 0.77$ & 0.32 \\
\hline \multicolumn{5}{|l|}{ *Differential Lymphocytes } \\
\hline • T Lymphocytes \% & 43. $94 \pm 4.63$ & $35.11 \pm 4.80$ & $30.65 \pm 3.47$ & $0.003 *$ \\
\hline - T Lymphocytes absolute (10VL). & 2. $54 \pm 0.43$ & $1.99 \pm 0.34$ & $1.80 \pm 0.29$ & $0.009 *$ \\
\hline - CD4 helper \% & $47.38 \pm 7.36$ & $40.47 \pm 7.89$ & $38.49 \pm 5.89$ & $0.033^{*}$ \\
\hline - CD4 helper absolute $\left(10^{3} / \mathrm{L}\right)$ & $1.19 \pm 0.21$ & $0.95 \pm 0.18$ & $0.78 \pm 0.12$ & $0.010^{*}$ \\
\hline - CBS Cytotoxic\% & $28.36 \pm 3.52$ & $24.58 \pm 4.34$ & $23.67 \pm 4.49$ & 0.78 \\
\hline - CDS Cytotoxic absolute $\left(10^{3} / \mathrm{L}\right)$ & $0.63 \pm 0.12$ & $0.54 \pm 0.06$ & $0.52 \pm 0.13$ & 0.073 \\
\hline • CD56NK\% & $1.20 \pm 0.20$ & $0.63 \pm 0.14$ & $0.23 \pm 0.00$ & $0.003 *$ \\
\hline - CD56 NK absolute $\left(10^{3} / \mathrm{L}\right)$ & $0.03 \pm 0.01$ & $0,02 \pm 0.00$ & $0.01 \pm 0.00$ & $0.004 *$ \\
\hline - $\mathrm{CD} 14$ monocytes \% & $85.24 \pm 3.002$ & $81.80 \pm 2.58$ & $75.33 \pm 2.20$ & $0.015^{*}$ \\
\hline - $\mathrm{CD} 14$ monocytes absolute $\left(10^{3} / \mathrm{L}\right)$ & $11 \pm 0.33$ & $1.98 \pm 0.41$ & $1.64 \pm 0.26$ & $0.037^{*}$ \\
\hline • B lymphocytes (CD19\&CD20)\% & 6. $16 \pm 1.33$ & $7.61 \pm 1.02$ & $8.00 \pm 1.80$ & 0.50 \\
\hline - B lymphocytes (CD $19 \&$ CD20) absolute $\left(10^{3} / \mathrm{L}\right)$ & $0.18 \pm 0.04$ & $0.18 \pm 0.05$ & $0.19 \pm 0.06$ & 0.98 \\
\hline \multicolumn{5}{|l|}{ Imimiiiioglobulin \& immune proteins } \\
\hline • $\operatorname{IgM}(\mathrm{mg} / \mathrm{dl})$ & $169.90 \pm 18.50$ & $176.60 \pm 12.69$ & $177.20 \pm 22.85$ & 0.75 \\
\hline - $\operatorname{IgG}(\mathrm{mg} / \mathrm{dl})$ & $1469.43 \pm 110.6$ & $1612.32 \pm 190.8$ & $1660.73 \pm 222.59$ & 0.10 \\
\hline \multicolumn{5}{|l|}{ Complement } \\
\hline • $\mathrm{C} 3(\mathrm{mg} / \mathrm{dl})$ & $158.43 \pm 5.34$ & $164.93 \pm 14.52$ & $165.04 \pm 10.28$ & 0.180 .38 \\
\hline - $\mathrm{C} 4(\mathrm{mg} / \mathrm{dl})$ & $38.58 \pm 5.27$ & $37.87 \pm 3.88$ & $35.89 \pm 2.54$ & \\
\hline
\end{tabular}

* Statistical significant at $\mathrm{P}<0.05$

Table (2). Relation between Stress and Immune Response among Breast Cancer Women in the Post-operative Phase.

\begin{tabular}{|c|c|c|c|c|}
\hline \multirow{4}{*}{ Pre-operative assessment of immune response } & \multicolumn{3}{|c|}{ Degree of Pre-operative stress assessment } & \multirow{4}{*}{ F test/ P Value } \\
\hline & Mild & \multirow{2}{*}{$\begin{array}{l}\text { Moderate } \\
(\mathrm{n}=\mathbf{2 2})\end{array}$} & \multirow{2}{*}{$\begin{array}{l}\text { Severe } \\
(\mathrm{n}=22)\end{array}$} & \\
\hline & \multirow{2}{*}{$\begin{array}{l}(n=16) \\
X \pm S D\end{array}$} & & & \\
\hline & & $\mathbf{X} \pm \mathrm{SD}$ & $\mathbf{X} \pm \mathbf{S D}$ & \\
\hline - Total leukocyte counts $(\mathrm{KP} / \mathrm{L})$. & $6.31 \pm 0.46$ & $6.68 \pm 0.83$ & $7.24 \pm 1.18$ & 0.091 \\
\hline \multicolumn{5}{|l|}{ *Differential Lymphocytes } \\
\hline - T Lymphocytes \% & $41.20 \pm 2.10$ & $36.58 \pm 1.88$ & $29.80 \pm 1.12$ & $0.007 *$ \\
\hline - T Lymphocytes absolute (10VL). & $2.47 \pm 0.55$ & $1.90 \pm 0.42$ & $1.79 \pm 0.14$ & $0.025^{*}$ \\
\hline - CD4 helper \% & $45.14 \pm 70.06$ & $39.29 \pm 5.25$ & $30.82 \pm 2.65$ & $0.001 *$ \\
\hline - $\mathrm{CD} 4$ helper absolute $\left(10^{3} / \mathrm{L}\right)$ & $1.25 \pm 0.13$ & $0.85 \pm 0.08$ & $0.70 \pm 0.04$ & $0.002 *$ \\
\hline - CBS Cytotoxic\% & $30.58 \pm 4.27$ & $26.11 \pm 5.03$ & $22.26 \pm 3.25$ & $0.040^{*}$ \\
\hline - CDS Cytotoxic absolute $\left(10^{3} / \mathrm{L}\right)$ & $0.61 \pm 0.06$ & $0.58 \pm 0.07$ & $0.50 \pm 0.05$ & $0.009^{*}$ \\
\hline - $\mathrm{CD} 56 \mathrm{NK} \%$ & $3.28 \pm 0.37$ & $2.51 \pm 1.20$ & $1.66 \pm 0.12$ & $0.001 *$ \\
\hline - CD56 NK absolute $\left(10^{3} / \mathrm{L}\right)$ & $0.04 \pm 0.01$ & $0.02 \pm 0.00$ & $0.01 \pm 0.00$ & $0.001^{*}$ \\
\hline - CD 14 monocytes \% & $82.99 \pm 2.00$ & $78.86 \pm 1.93$ & $73.06 \pm 1.68$ & $0.007 *$ \\
\hline - CD 14 monocytes absolute $\left(10^{3} / \mathrm{L}\right)$ & $2.00 \pm 0.30$ & $1.90 \pm 0.28$ & $1.61 \pm 0.24$ & $0.016^{*}$ \\
\hline • B lymphocytes (CD19\&CD20)\% & $5.84 \pm 0.50$ & $6.69 \pm 0.24$ & $6.71 \pm 0.53$ & 0.65 \\
\hline - B lymphocytes (CD $19 \&$ CD20) absolute $\left(10^{3} / \mathrm{L}\right)$ & $0.17 \pm 0.03$ & $0.18 \pm 0.04$ & $0.19 \pm 0.05$ & 0.27 \\
\hline \multicolumn{5}{|l|}{ Imimiiiioglobulin \& immune proteins } \\
\hline • $\operatorname{IgM}(\mathrm{mg} / \mathrm{dl})$ & $175.26 \pm 27.26$ & $176.63 \pm 30.21$ & $187.82 \pm 35.21$ & 0.63 \\
\hline - $\operatorname{IgG}(\mathrm{mg} / \mathrm{dl})$ & $1546.0 \pm 215.24$ & $1671.25 \pm 370.77$ & $1755.88 \pm 2781$ & 0.52 \\
\hline \multicolumn{5}{|l|}{ Complement } \\
\hline - $\mathrm{C} 3(\mathrm{mg} / \mathrm{dl})$ & $167.57 \pm 13.88$ & $167.94 \pm 11.00$ & $180.00 \pm 33.74$ & 0.52 \\
\hline - $\mathrm{C} 4$ (mg/dl) & $36.50 \pm 6.90$ & $43.53 \pm 11.64$ & $44.26 \pm 13.84$ & 0.45 \\
\hline
\end{tabular}

* Statistical significant at $\mathrm{P}<0.05$ 
Table (3). Relation between Stress and Wound Assessment among Breast Cancer Women in the Post-operative Phase.

\begin{tabular}{|c|c|c|c|c|c|c|c|}
\hline \multirow{3}{*}{ Wound assessment } & \multicolumn{6}{|c|}{ Stress Degree } & \multirow{3}{*}{ P value } \\
\hline & \multicolumn{2}{|c|}{ Mild $(n=10)$} & \multicolumn{2}{|c|}{ Moderate (n=16) } & \multicolumn{2}{|c|}{ Severe $(n=34)$} & \\
\hline & No & $\%$ & No & $\%$ & No & $\%$ & \\
\hline \multicolumn{8}{|l|}{ Wound inflammation } \\
\hline Present & 4 & 40.0 & 8 & 50.0 & 18 & 52.9 & 0.70 \\
\hline Absent & 6 & 60.0 & 8 & 50.0 & 16 & 47.1 & Not sig \\
\hline \multicolumn{8}{|l|}{ Extent of inflammation } \\
\hline Absent & 6 & 60.0 & 8 & 50.0 & 16 & 47.1 & \\
\hline Very slight $(<0.5 \mathrm{Cm})$ & 2 & 20.0 & 2 & 12.5 & 6 & 17.6 & \\
\hline Slight $(0.5-<1 \mathrm{Cm})$ & 2 & 20.0 & 4 & 25.0 & 6 & 17.6 & 0.62 \\
\hline Moderate $(1-2 \mathrm{Cm})$ & 0 & 0.00 & 2 & 12.5 & 4 & 11.8 & Not sig \\
\hline Extensive (3 $\mathrm{Cm}$ or more) & 0 & 0.00 & 0 & 0.00 & 2 & 5.9 & \\
\hline \multicolumn{8}{|l|}{ Pain in wound } \\
\hline Present & 0 & 0.00 & 6 & 37.5 & 28 & 82.4 & $0.020 *$ \\
\hline Absent & 10 & 100 & 10 & 62.5 & 6 & 17.6 & Not sig \\
\hline \multicolumn{8}{|l|}{ Wound discharge } \\
\hline Present & 2 & 20.0 & 6 & 37.5 & 14 & 41.2 & 0.063 \\
\hline Absent & 8 & 80.0 & 10 & 62.5 & 20 & 58.8 & Not sig \\
\hline \multicolumn{8}{|l|}{ Type of discharge } \\
\hline Absent & 8 & 80.0 & 10 & 75.0 & 20 & 70.6 & 0.12 \\
\hline Serum & 2 & 20.0 & 4 & 12.5 & 8 & 11.8 & Not sig \\
\hline Blood & 0 & 0.00 & 2 & 12.5 & 6 & 17.6 & \\
\hline \multicolumn{8}{|l|}{ Redness and hotness } \\
\hline Present & 2 & 20.0 & 4 & 25.0 & 10 & 29.4 & 0.050 \\
\hline Absent & 8 & 80.0 & 12 & 75.0 & 24 & 70.6 & Not sig \\
\hline
\end{tabular}

*Sig. $=$ Statistical significant $<0.05$

Not Sig.= Not statistical significant

Table (4). Correlation between Stress and Laboratory Investigations among Breast Cancer Women in the Post-operative Phase.

\begin{tabular}{lll}
\hline $\begin{array}{l}\text { Post operative } \\
\text { laboratory }\end{array}$ & \multicolumn{2}{l}{$\begin{array}{l}\text { Post- operative total stress in breast cancer } \\
\text { patients }\end{array}$} \\
\cline { 2 - 3 } investigations & $\mathbf{R}$ & p-value \\
\hline Hemoglobin & -0.444 & $0.014^{*}$ \\
Hematocrit & -0.540 & $0.002^{*}$ \\
Blood urea & $0.373-$ & $0.042^{*}$ \\
Serum creatinine & 0.103 & 0.589 \\
Serum albumin & $0.449-$ & $0.013^{*}$ \\
Albumin/ Globin ratio & $0.329-$ & 0.076 \\
\hline
\end{tabular}

* Statistical significant at $\mathrm{P}<0.05$

$\mathrm{r}=$ person correlation

$\mathrm{P}=$ level of significance

\section{Discussion}

The current study's aim is to determine the effect of stress on immune responses of breast cancer women after Mastectomy,

Regarding the Sociodemographic characteristics of the study sample, revealed that the age of most of the studied sample ranged between 45 to less than 55 years. This result is in agreement with that reported by Ibrahim, ${ }^{(19)}$ and Omar et al., (20) noted that breast cancer in Egyptian patients has a younger age distribution with the majority of cases occurring at 30-60 years of age, The median age is 46 years, in relation to family history of breast cancer, the majority of the sample had no family history of breast cancer., this result is in agreement with that reported by Magnusson et al., ${ }^{(21)}$ noted that approximately five percent of new breast cancers are attributable to hereditary syndromes, while no etiology is known for the other ninty five percent $(95 \%)$ of cases, and approximately ten to fifteen percent of all breast cancers are thought to be familial. In other study carried out by Linton $\&$ Maelius., ${ }^{(22)}$ noted that familial aggregation can be attributed in part due to the shared physical, environmental, and life style factors.

On the contrary, Sharon, et al ${ }^{(23)}$ stated that positive family history of breast cancer including close relative, increases significantly women with risk of developing breast cancer. Another study was carried by Bernadin., ${ }^{(24)}$ noted that a large number of risk factors have been identified that modify a women with likelihood of developing breast cancer, they briefly listed family history including first degree relative with breast cancer.

The effect of Sociodemographic characteristics on the stress degree among the study sample was also analyzed. Results showed that there was statistical significant difference between Pre-operative and post operative stress assessment and Sociodemographic characteristics among the studied sample regarding age group, as the highest numbers of women had severe degree of stress were presented among the age group of 35 to less than 45 years old. and the income level at the post operative assessment as the highest numbers of patients had severe degree of stress were presented among the income level 150 to less than 500 Egyptian pounds. This result is in agreement with that reported by Hopwood., (25) and Maunsell, et al (26) they noted that the effect of age, younger subjects showed greater body image disturbance, anxiety and depression, younger women less than 50 years of age reported significantly greater overall symptom of distress than older women.

Regarding to stress degree at pre and post operative stress 
assessment. Less than half of the sample had severe stress. In contrast more than half of the sample had severed degree of stress at the post-operative assessment. This result is supported by Spencer, et al ${ }^{(27)}$ who noted that woman with cancer is faced with a number of issues like death, disfigurement, disability, dependence, and disruption of relationship. In addition cancer of the breast raise concern related to sexuality, femininity, and feeling of motherhood.

Moreover Cohen \&Rabin ${ }^{(28)}$ and Anderson, et al. ${ }^{(29)}$ noted that breast cancer diagnosis is a stressor of considerable magnitude. One particular source of stress is worry that the disease will recur. Indeed, we have observed that at least half of newly diagnosed women worry at the time of surgical treatment about possible disease evolution and the recurrence of cancer in the first year after diagnosis. In addition Wein ${ }^{30}$ reported that difficulties in women after mastectomy. Many women are dissatisfied with any prosthesis that they are offered, and they may attempt to avoid facing the painful reality of their loss by refusing to look at their chest wall or allowing their partners to do so. Some go to dressing and undressing in the dark, and minimizing the time that they spend bathing. These activities reflect an avoidant style of coping. It is hardly surprising that these women tend to have lasting depression and loss of interest in sexuality.

The results of the current study showed that there was statistical significant differences as the higher the degree of stress the lower the mean values of $\mathrm{T}$ Lymphocyte, CD4 helper, CD56 NK, and CD14 Monocytes in pre operative assessment and in post operative assessment, and CD8 Cytotoxic in post operative assessment. This result is supported by Sadek\&Nemeraff ${ }^{31}$ and Irwin $^{32}$ noted that a diagnosis of breast cancer and subsequent T-cell activity. They speculate that patients with impaired immune system may be less able to resist progression of the cancer and metastatic spread. Also Casey,et al (33) showed that the physiologic effects of stress inhibit cellular immune responses that are relevant to cancer prognosis, including NK cell toxicity and T cell responses, and the NK cells in women in the high stress group were destroyed than were in the low stress group. surgery are highly stressful events which can lead to chronic stress and found that women with higher stress levels had impaired immune function as indicated by lower NK cell lyses (ability to destroy cells), and decreased T-cell activity. They speculate that patients with impaired immune system may be less able to resist progression of the cancer and metastatic spread. Also Andersen et al." (30) showed that the physiologic effects of stress inhibit cellular immune responses that are relevant to cancer prognosis, including NK cell toxicity and T cell responses, and the NK cells in women in the high stress group were destroyed than were in the low stress group.

It was explained according to Wein, ${ }^{(31} \&$ Irwin $\left.{ }^{32}\right)$ they stated that in chronic stress, the part of the brain that controls the stress response is going to be constantly pumping out a lot of stress hormones. The immune cells are being bathed in molecules which are essentially telling them to stop fighting. So in situations of chronic stress the immune cells are less able to respond to an invader like a bacteria or a virus. In turn, hormone such as cortisol influences the immune response. Cortisol is the major steroid hormone produced by bodies to help get through stressful situations. The related compound known as cortisone is widely used as an anti-inflammatory drug. World Health Organization ${ }^{34}$ noted that chronic activation of cortisol, the body's response to stress, can produce unhealthy physiological outcomes. Some of these include: increased blood pressure, immune suppression, osteoporosis, muscle atrophy..

Regarding Correlation between total leukocyte counts and laboratory investigations among breast cancer women in the post-operative period. There was statistical significant negative correlation between total leukocyte counts and post operative laboratory investigations of the studied sample for hemoglobin, hematocrit, and serum albumin. This result is supported by American Cancer Society ${ }^{35}$ they noted that the acquired failure of host immunocompetence that may result from significant protein and caloric malnutrition has been associated with an increased incidence of septic complications in women undergoing operation.

\section{Conclusions}

Based on results of this study, the following conclusions could be reached:

- Increasing level of stress by decreasing age and income level among breast cancer women following mastectomy.

- The higher the degree of stress, the lower the values of T Lymphocytes, CD4 helper, CD8 Cytotoxic, CD56 NK cells, and CD14 Monocytes.

- The majority of the sample presented with pain in the wound had severe level of stress.

\section{Recommendations}

Based on the findings of the present study, the following recommendations are derived and suggested:

1. Developing written guidelines about caring for women, and stress management after mastectomy.

2. Health teaching for the women to cope with physical, emotional, and stress associated post-operative complications (as lymphedema) and its nursing management and treatment. :

3. Further researches are needed with large sample size and control group.

\section{References}

[1] World Health Organization. (2006). Breast cancer facts, Available http://www.medterms.com/script/main/art.asp?2580.

[2] Nucleus medical art. (2004). Living with breast cancer. Available at: http:/www.yourmedicalsource.com/library/breast cancer/BRCliving.htm 
[3] American Cancer Society, (2007). What Happens After Treatment for Breast Cancer, Available at: http://www.webmd.com/breast-cancer/guid/getting-support.

[4] Elatar, I., (2001). Cancer registration, National Cancer Institute, Available at: http://www.nci.edu.eg/journal/nci2001 $20 \%$ pdf.

[5] Omar, S., Khaled, H., Gaafar, R., Zekry, A., Eissa, S., and El Khatib, O. (2003). Breast cancer in Egypt: A review of disease presentation and detection strategies. Eastern Mediterranean health journal, 9 (3): 448 -63.

[6] Statistical records of Menoufyia University Hospital. (2004).

[7] Apantaku, L.M. (2002). Breast conserving surgery for breast cancer, American Family Physician, 66 (12 ): 2271-81.

[8] Black, J.M., and Hawks, J.H. (2005). Medical Surgical Nursing, 7th ed., USA, Elsevier Saunders, 1092, 1103-1123

[9] Maguire, P. (1998). coping with loss: surgery and loss of body parts, British Medical Journal, 316 (7137)s: 1086-88.

[10] Andersen, B.L., Glaser, R., and Kiecolt-Glaser, J. K. (1994). A biobehavioral model of cancer, stress, and disease course. American Psychologist, 49 (12): 389-404.

[11] Smeltzer, S.C., and Bare, B.G. (2000). Textbook of medical surgical nursing, 9th ed., New York, William Wilkins company, 72 .

[12] Watkins, K.M. (1997). Mind body medicine: A clinician's guide to psychoneuroimmunology. New York, Churchill Livingstone, 85.

[13] Smeltzer, S.C., and Bare, B.G., (2004). Textbook of Medical Surgical Nursing, 10th ed., London; Walters Kluwer Company, 84-8, 1446-55, 1521-31.

[14] Dean G.E, Haeuber D., and Rivera L. (1996). Cancer Nursing: A Comprehensive Textbook. 2nd ed., Philadelphia, W.B. Saunders Company, 963-78.

[15] Lewis, S.M., Collier, I.C., and Heitkemper, M. (1996). Medical surgical nursing, 4th ed., London, Mosby, 1542-61.

[16] Weiss .I \& Marmer A. (1997). Immunity, Available at: http://www.drweil.com/database/display/0,1412,69,00.htm1.

[17] O'Leary.M (2002). the immune system; Available at http://www.cancerhelp.org.uk/help/defaultasp.page $=118$.

[18] Gaber, A. (1986). Cancer profile in Gharbiah, Egypt. Methodology and results, Cairo, Ministry of health and population, Egypt and Middle East Cancer Consortium.

[19] Ibrahim,1 (2000). Cancer statistics, CA, 42 (1): 19.

[20] Omer,kh. (2004). The Lippincolt Manual Of Nursing Practice. 2nd ed., Philadelphia, Lippincolt - Raven Publisher. 99-112.

[21] Magnusson, C., Colditz, G., Rosener, A., Bergdtrom, R.,
Presson, I. (1998). Association of family history and other risk factors with breast cancer risk. Cancer causes and control; 9 (7): 259-67.

[22] Linton, A., and Maelius, N. (2003). Introduction to medical surgical nursing, 3rd ed., Philadelphia, Saunders Company. Rubbin, S.L., Kumar, V., Carton, R.S. (2003). The female genital system and breast: Rubbins basic pathology. 7th ed., Philadelphia, London W.B. Saunders. Company.

[23] Sharan, P., Kulhara, P., Sharma, S. (2003). Stress and coping in women with breast cancer in India, German Journal Of Psychiatry, 2 (7): 40-48.

[24] Bernadine, C. (1999). Symptom distress in women newly diagnosed breast cancer, Cancer Nursing, 22 (3): 185 - 94.

[25] Hopwood, P. (1993). The assessment of body image in cancer patients, European Journal Of Cancer, 23 (2): $276-81$.

[26] Maunsell, E., Brisson, J., and Deschênes, L. (1996). Randomized trial of a psychological distress screening program after breast cancer: Effects on quality of life. J Clin Oncol, 14 (3) : 2747-55,

[27] Spencer, S., Lehman, J., and Wynings, C. (1999). Concerns about breast cancer and relations to psychosocial well-being in a multi-ethnic sample of early-stage patients. Health Psychol, 18 (6): 159-168.

[28] Cohen, S., and Rabin, B.S. (1998). Psychological stress, immunity, and cancer; Journal of The National Cancer Institute, 90 (1): 23- 34.

[29] Andersen, BL., Kiecolt, J., and Glaser, R. (1998). A biobehavioral model of cancer stress and disease course, Psychosom Med , 49 (4): 389-404.

[30] Wein, H. (2000). Stress and Disease: New Perspectives: http://nih.gov/news/wordonhealth/oct2000/story01.htm-19k.

[31] Sadek, N., Nemeroff, C.B. (2000). Update On The Neurobiology Of Depression. Journal of the American Medical Association, 284 (14): 1837-38.

[32] Irwin, M. (2000). Psychoneuroimmunology of depression. Part of the fourth generation of progress. American College of neuropsychopharmacology: Available at: http://www.acnp.org/G4/GN401000098.

[33] Casey, J., Flinn, W.R., Yao, J.S., Fahey, V., Pawlowski, J., Bergan, J.J. (1993). Correlation of immune and nutritional status with wound complications in patients undergoing vascular operations. Am Surgery, 93 (6):822-7.

[34] World Health Organization. (2004). Breast cancer facts, Available http://www.medterms.com/script/main/art.asp?2580.

[35] American Cancer Society, (2005). What Happens After Treatment for Breast Cancer, Available at: http://www.webmd.com/breast-cancer/guid/getting-support. 